\title{
Ensaio
}

\section{A formação prática no estágio curricular: uma oportunidade a ser explorada na extensão}

The practical experience: an opportunity to be explored in the extension

\section{Introdução}

As reflexões deste ensaio são resultado de muitos anos no exercício da docência, pesquisa e extensão, na área das ciências sociais aplicadas e na sociologia. ${ }^{1} \mathrm{Um}$ dos problemas mais debatidos sobre a extensão universitária está relacionado com a sua função quando comparada com o ensino e com a pesquisa, o que envolve muitos esforços para a sua definição. Frequentemente associam-se as ações da extensão às atividades externas oriundas de diferentes setores da Universidade por meio dos seus segmentos: professores, alunos e funcionários. Isto é, uma ação "fora dos seus muros", além da sala de aula. Entretanto, para muitos, a iniciativa docente deve ser privilegiada porque este segmento apresentaria condições ou qualificações mais favoráveis para a apresentação de projetos. Em geral, atividades como cursos de extensão, palestras, seminários, simpósios e produção audiovisual são classificadas como extensionistas, pois atingem ao público externo, principal objetivo desta ação. Deste modo, oferecem à população os resultados alcançados pela instituição de ensino superior, cujo investimento do Estado será legitimado e reconhecido socialmente. No caso do Brasil, onde existe uma série de incentivos indiretos ao sistema privado da educação, impõem-se algumas demandas nesta direção. Entretanto, as universidades públicas apresentam um número muito superior de projetos de pesquisa e extensão, se comparadas com as universidades privadas.

A concepção mais "teórica" do conhecimento ainda tem uma expressão significativa no debate sobre a produção científica. Embora sejam visíveis os avanços realizados na área da extensão universitária, é muito comum observar uma associação mais direta do fazer científico com os projetos de

\begin{abstract}
Resumo
Este ensaio tem como objetivo apresentar algumas reflexões sobre a aplicabilidade do conhecimento na sociedade contemporânea e o potencial que a formação prática tem para favorecer um avanço neste debate. A partir de uma comparação entre a ação extensionista e as experiências de estágio supervisionado, são exploradas as diferentes alternativas para consolidar a extensão como um meio importante de consolidação metodológica de experiências de ensino.

Palavras-chaves: Extensão; Estágio supervisionado; Educação
\end{abstract}

Área Temática: Educação

Linha de Extensão: Metodologias e estratégias de ensino/aprendizagem

' Instituição: UERJ - Programa de Estudos de Gênero, Geração e Etnia: demandas sociais e políticas públicas. sub-Reitoria de Extensão e Cultura. Faculdade de Serviço Social.

E-mail: dayse@centroin.com.br 
pesquisa e atividades de ensino, pois fundamentariam mais eficazmente o objeto de estudo e, consequentemente, as ações sobre ele. A percepção referente à produção do conhecimento se baseia na premissa de uma metodologia específica, com parâmetros considerados mais científicos, o que permite compreender a realidade com o distanciamento e a qualificação necessários. O domínio destas aptidões seria viabilizado pela pesquisa e incentivado nas formas de ensino por métodos didáticos em sala de aula. Entretanto, apesar dos avanços observados na sistematização das ações extensionistas, algumas perguntas se mantêm e surgem com mais frequência do que aquela que se esperava, como por exemplo: $\mathrm{O}$ que faz um pesquisador e o que faz um "extensionista"?; O que justifica programas diferenciados, recursos diferenciados, propostas diversas?

O conhecimento é da dimensão humana e tem sido considerado o centro das transformações no mundo, impulsionado pelas grandes descobertas na passagem do século XIX para o XX, no mundo ocidental. A referência científica se tornou um padrão de linguagem e parâmetro de "verdade" que interfere em toda a organização da sociedade contemporânea e estrutura o sistema educacional em grande parte dos países. Disseminam-se modelos técnico-operacionais que são elaborados conforme novos métodos científicos que impulsionam mudanças significativas no modo de viver em diferentes regiões do planeta. Em grande parte, estas inovações são experimentadas, testadas e criadas na universidade, a partir dos níveis mais elevados de conhecimento e, particularmente, da formação profissional. Portanto, a universidade tem uma função essencial neste processo. $O$ que precisa ser mais discutido e questionado é a relação entre a dimensão prática e a abstrata do conhecimento sobre a realidade que nos cerca, na qual estamos imersos e desenvolvemos o debate sobre a extensão. Esta é a motivação para escrever este texto.

\section{A Extensão, a mediação e a ação externa}

A "relação entre a teoria e a prática" é frequentemente colocada como o " $\mathrm{x}$ " do problema relacionado ao conhecimento moderno. Ao menos no dito popular isto já foi "incorporado". Para ilustrar as lacunas, as fragilidades, as incongruências, falhas de algum plano, de alguma expectativa criada na implantação de políticas ou projetos, a célebre frase: na teoria é uma coisa, mas na prática é outra já se consagrou como um recurso de linguagem para muitos expressarem a sua desconfiança, a sua descrença, o seu desestímulo para tentar efetivar mudanças ou uma forma de fazer algo inovador. Até mesmo com base em uma receita de bolo: faltou o ingrediente diferenciador - o "olho" consagrado na execução diária ou frequente da mesma ação, à medida que se calcula com a mão na massa..., etc. A perspectiva popular, de alguma forma, revela o possível distanciamento deste universo do saber, do conhecimento protocolado pela universidade e a realidade cotidiana vivida pela maioria das pessoas, pelos grupos, na sociedade. Durante o debate, fica a impressão de que a relação entre a teoria e a prática será mediada pela metodologia a ser estabelecida de forma coerente, substantiva e relevante durante a produção de novos conhecimentos; e a relação da universidade com a sociedade será mediada pela extensão, que se utiliza destes conhecimentos. O que fixa a função da extensão é a comunidade externa. Sem a relação com a comunidade externa não existe a extensão. Portanto, estabelece a interseção entre a universidade e a comunidade externa - a população, representada de diversas formas, de diferentes modos, por meio de diferentes grupos.

O processo do conhecimento tem provocado uma ampla discussão sobre a sua natureza e os seus fins ou que direção deve tomar a formação científica. Existe uma antiga controvérsia sobre a existência necessária ou não de hierarquias entre graus ou tipos de conhecimento. A estrutura das redes de ensino estabelece etapas de aprendizado de acordo com o desenvolvimento cognitivo das pessoas, cujas premissas são resultado de estudos científicos oriundos de áreas como a de humanidades e biomédicas com base em faixas etárias, medição de desempenho neurológico etc. As primeiras influenciaram com uma importante contribuição das teorias psicológicas e psicanalíticas, impulsionando metodologias que integraram a dimensão emocional e cerebral do comportamento humano. As segundas contribuíram a partir de teorias neurocientíficas que se tornam parâmetros para algumas áreas da pedagogia e da psicologia ou provocam um debate que pode favorecer um diálogo entre áreas diferenciadas de saber. Entretanto, sem dúvida, são estabelecidas hierarquias entre estes graus de conhecimento e, particularmente, entre as diferentes áreas do conhecimento.

O conhecimento é um instrumento de poder, pois todo grupo que domina um tipo de saber 
que favorece o acesso a metodologias científicas que oferecem recursos cognitivos que instrumentalizam a reflexão autônoma e questionadora da realidade, contribui para uma forma de agir no mundo mais independente, o que sempre afetará a estrutura hierárquica estabelecida. Esta hierarquia influencia a lógica da ocupação de postos de comando em organizações e confere prestígio, força e, portanto, poder. O grupo profissional, cuja formação se tornou um fenômeno estudado pela sociologia, revela como funcionam os mecanismos criados por seus membros para manter o monopólio do saber e para mantê-lo restrito àquele que corresponda às exigências instituídas pelo próprio grupo. Assim foram estabelecidas as condições para a existência das guildas na Idade Média que, reunindo artesãos ou pequenos comerciantes, cujas habilidades se tornavam os critérios para a inclusão, influenciaram um modelo de associação profissional. O saber específico torna-se uma espécie de moeda a definir o valor de uma atividade laborativa e a diferenciar novos grupos, constituindo identidades com base neste saber. A sociedade moderna se afirma a partir desta perspectiva e dá lugar a organização técnico-cientifica que assistimos contemporaneamente, na qual o mercado de trabalho dita as condições que o candidato a uma vaga deve apresentar para ser incluído e afirma novos grupos de poder que interferem na dinâmica social e política, movida por interesses econômicos.

Esta tendência sustenta uma polêmica e interminável controvérsia que se mantém e afeta a universidade, pois relaciona permanentemente o mercado de trabalho ao espaço universitário. Qual deve ser a base desta interação? Esta questão apresenta o ponto mais controverso. A origem deste debate está no avanço da sociedade industrial que demanda pessoal preparado tecnicamente para as sua crescente exigência e inovação tecnológica e que configura um mercado de trabalho cada vez mais dinâmico e rápido em constituir novos postos de trabalho. $\mathrm{O}$ conhecimento mais humanístico, de apelo mais libertário, associado ao iluminismo centrado na revolução das ideias como forma de ascensão humana, a partir do acesso ao livre pensar e conseguintemente, agir, vai sendo aos poucos substituído por um discurso mais pragmático que aspira a instrumentação para ascensão social na nova ordem econômico-capitalista. Essa "dualidade" parece persistir nos discursos observados nos debates sobre o papel da universidade, seus fins e como operacionalizar a articulação entre o ensino, pesquisa e extensão univer- sitária. A função social da universidade é demandada e formas de garanti-la são discutidas. Neste caso, é demandada tanto para as instituições públicas como para os estabelecimentos educacionais privados. As primeiras seriam pressionadas pela própria natureza da instituição - pública, cuja obrigação em garantir esta função é praticamente constitucional. Os segundos são pressionados por um discurso político-ideológico, constituindo-se quase uma obrigação ética e moral, oferecer "sem fins lucrativos" atividades educativas para a comunidade externa, como uma devolução do que foi investido pelo Estado em subsídios fiscais na empresa educacional. Estas preocupações ainda dão margem à outra polêmica que se evidencia nas avaliações das parcerias público-privado (PPPs) no universo do conhecimento científico. São debatidas as formas de fomento em pesquisas, os incentivos a projetos por parte de empresas privadas e a intermediação de recursos do Estado nestas propostas.

Esta controvérsia atinge as ações de extensão quando, por exemplo, o fato de um curso proposto para a comunidade externa, financiado por uma empresa interessada e oferecendo vagas para os seus empregados como contrapartida, torna-se alvo de questionamento por parte de grupos que entendem esta experiência como uma ameaça a "integridade universitária”, contrariando normatizações já previstas para estas ações. Portanto, é importante considerar estas críticas como ponto de tensão neste debate e diante de várias iniciativas que expressam o interesse em avançar na perspectiva extensionista, abrindo os portões da universidade e, ao mesmo tempo, viabilizando recursos para a instituição. Estas parcerias só têm a colaborar para o avanço técnico-científico, caso os parâmetros éticos e profissionais sejam seguidos e os resultados alcançados evidenciem vantagens para o aprendizado e capacitação profissional de alunos em formação - atividade prioritária da universidade. Neste sentido, a experiência de estágio pode ser avaliada como uma potencial oportunidade para instituir a mediação com a comunidade externa por meio da extensão e, afirmando a articulação com o ensino e a pesquisa.

\section{A formação prática por meio do estágio curricular: uma oportunidade a ser mais explorada na extensão}

A ideia não é nova: fazer do estágio curricular uma alternativa de ação na extensão universitária. Algumas iniciativas já foram experimentadas nesta 
direção. Entretanto, observa-se que são intermitentes, sem uma sistematização que fortaleça a sua viabilidade como uma meta estruturante da formação prática das carreiras profissionais. Outro problema a ser discutido é o motivo de poucos cursos exigirem em seus currículos, obrigatoriamente, a formação prática, por meio de estágios no mercado de trabalho. Penetrar neste campo de formação - o da prática - implica em retomar o problema dos graus e natureza do conhecimento. Inclusive, implica em até mesmo discutir as formas de classificação das áreas de conhecimento dos órgãos de fomento no Brasil.

A extensão não deve ser pensada apenas como mediação entre o mundo externo e interno a universidade, mas como alternativa metodológica no processo de aprendizado que pressuponha a relação com um interlocutor externo. Esta potencialidade precisa ser mais explorada neste debate. Neste sentido, o estágio curricular desenvolvido em instituições, empresas e organizações não governamentais com a supervisão de um profissional interessado em participar da formação de novos talentos é uma proposta promissora. $\mathrm{O}$ estímulo para a criação de vagas de estágio neste mercado tem sido crescente. Já existem empresas, inclusive com este fim: intermediar o preenchimento de vagas como um serviço prestado tanto para a universidade como para as empresas. Este sistema tem interessado mais às empresas, pois encontram pessoal para desenvolver atividades que não seriam destinadas a um profissional qualificado tendo em vista outras exigências da rotina de trabalho. Este pode ser motivado a supervisionar o aprendizado do estagiário. Para o mercado de trabalho, os bancos de vagas de estágio são atrativos, considerando a necessidade que tem de absorver jovens talentos.

Entretanto, observa-se certo descompasso entre este movimento do mercado quanto ao estágio e o da universidade. Não se remete aqui às coordenações, departamentos ou setores responsáveis pelo levantamento, divulgação e por medidas de estímulo a criação de vagas de estágio no interior do espaço universitário. O que está em foco é a necessidade de existir um estímulo mais sistemático para a inclusão da formação prática nos currículos dos cursos universitários, seja em que área for. A partir deste movimento, seria importante repensar a própria classificação das áreas de conhecimento como Ciências Sociais Aplicadas e Ciências Humanas, por exemplo. É curioso observar este tipo de classificação em um momento de tantas mudanças no ambiente científi- co, quando se discute as possibilidades do conhecimento compartilhado e multidisciplinar.

$O$ fato é que existe uma separação entre o pensar e o fazer. São momentos distintos de um mesmo processo: a produção de conhecimentos e a aplicabilidade destes conhecimentos. Entretanto, devem ser considerados como etapas distintas da mesma ação, portanto, imperativas para a sustentação de qualquer área de conhecimento. Considerando isto, como manter a classificação do tipo ciência social aplicada e a que não traz esta prerrogativa em seu título? Toda ciência tem como interesse ser aplicada, em algum momento do processo social ou da realidade cotidiana. Da biologia a sociologia. Hoje, com base nas alterações do sistema de ensino brasileiro, poderia ser incluída até mesmo a gastronomia (que, entre outras é contestada em seu status de ciência por grupos que não aceitam algumas inclusões na estrutura educacional por parâmetros definidos na sociologia das profissões). É fundamental perceber que esta classificação "aplicada" corresponde a áreas de conhecimento que pressupõem uma intervenção imediata na realidade, criando expectativas diretas de atendimento a demandas de serviços. Em geral, estas áreas de formação profissional, incluem em seus currículos a formação prática obrigatória, o que implica em oferecer vagas de estágio supervisionado. Mas muitos cursos não conseguem garantir uma estrutura eficaz para viabilizar a demanda criada para os alunos. Agrava este quadro, o fato de muitos dependerem do vínculo empregatício para se manterem ou as suas famílias, não tendo condições de se dedicar apenas aos estudos, o que dificulta a conciliação do horário de trabalho com o estágio supervisionado. A opção é adiar a conclusão do curso até encontrar uma solução possível na unidade de ensino. Uma destas alternativas tem sido buscar instituições ou projetos que ofereçam ações no fim de semana sob a supervisão de um profissional. Neste caso, há uma sobrecarga de responsabilidades que impõe limites para o desempenho do aluno, o que, em geral, retarda a conclusão do curso. Apesar de alguns cursos imporem a formação prática em seus currículos, a operacionalização desta exigência é difícil, enfrenta muitos obstáculos.

Pensar o estágio supervisionado como uma ação conjugada entre o ensino e a extensão é fortalecer o papel social da universidade, conforme os seus próprios interesses e atividades fim e oferece um novo status para a experiência de estágio. Não seria uma iniciativa isolada de alguns cursos que 
por "tradição" tem uma vinculação mais imediata com a dimensão interventiva de sua ação. Seria pensada uma nova estrutura pedagógica no ensino superior, a partir desta preocupação em aproximar a universidade da sociedade, por meio do mercado de trabalho.

\section{Pensando um modelo para a implementação de medidas que estimulem a articulação entre estágio e extensão}

É importante fazer um mapeamento preliminar de todos os cursos que apresentam o estágio supervisionado como uma exigência curricular na universidade e, a partir daí, oferecer a oportunidade de apresentarem as suas experiências e trocarem informações. Podem surgir novas opções para o avanço de cada um. Também podem surgir alguns impasses diante da natureza muito diferenciada dos cursos. Entretanto, o relevante é fazer um balanço do impacto do estágio na experiência do aluno e observar a avaliação deste segmento, dos professores responsáveis pela disciplina no curso e dos supervisores de campo. ${ }^{2}$

A partir desta etapa, com base nos dados fornecidos pelo setor responsável por estágios na universidade, deve ser feito um levantamento atualizado de todos os convênios cadastrados para inserção de alunos da instituição e estabelecida uma "linha do tempo", considerando os últimos dez anos. ${ }^{3}$ Desta forma, é possível observar flutuações nas ofertas de vagas por áreas de conhecimento e setores no mercado de trabalho, incluindo instituições públicas. Com base nestes resultados, pode ser feito um investimento para fortalecer parcerias que evidenciaram um compromisso duradouro com empresas e organizações não governamentais; efetivar redes de relacionamento com as instituições nos três níveis de governo: municipal, estadual e federal. Em seguida, elaborar um levantamento que relacione os cursos e as empresas, ONGs, instituições ao longo do período estabelecido (10 anos). A partir desta etapa, seriam observados os cursos que por mais tempo tem articulado estes convênios na universidade e se tem o estágio supervisionado como uma disciplina obrigatória no currículo.

Em seguida, seria estimulada a criação de opções para a formação prática de forma sistemática para os cursos que não a incluem como etapa obrigatória para a conclusão do curso, com base na avaliação daqueles que tem experiências bem sucedidas. No caso da grade curricular não permitir imediatamente a inclusão de uma disciplina especificamente com este fim, o que implicaria um trâmite burocrático maior, poderia ser estimulada a apresentação de projetos de extensão que favorecessem a aproximação com o mercado de trabalho. Estas iniciativas podem ser por meio de cursos de extensão que estimulem setores de interesse das carreiras universitárias a oferecerem vagas para a formação pratica dos alunos, tendo como contrapartida ações como estas, associadas a extensão. Neste ínterim, seriam experimentadas as possibilidades de formalização da disciplina de estágio supervisionado por meio de consultas às normatizações existentes, observando alternativas como alterações de grade curricular ou aproveitamento de opções já oferecidas como, por exemplo, atividades complementares até a configuração de um modelo mais visível de formação prática do aluno.

Os cursos que apresentassem estágio supervisionado entre as suas atividades acadêmicas regulares, previsto na grade curricular, poderiam ser estimulados a registrarem a experiência como um projeto de extensão, ampliando as possibilidades de oferecimento de contrapartidas aos setores que abrem vaga para estágio.

A proposta pode ser resumida em três passos:

$1^{\circ}$ passo - Levantamento dos cursos que oferecem estágio supervisionado curricular e avaliação da experiência.

2o passo - Levantamento atualizado dos convênios cadastrados na universidade por curso, nos últimos 10 anos.

3o passo - Estímulo à apresentação de projetos de extensão com base na experiência de estágio já desenvolvida pelas unidades de ensino que o incluem como disciplina obrigatória e observação de viabilidade de oferecimento de estágio supervisionado para os cursos que ainda não o fazem.

\section{Considerações finais}

A possibilidade de oferecer o estágio supervisionado como uma experiência em extensão universitária tem méritos que não foram explorados suficientemente. A vantagem não é, unicamente, o fato de agilizar a consolidação da mediação entre a universidade e a comunidade externa. Isto poderia ser feito de modo mais "burocrático": divulgação do número de empresas e instituições conveniadas para desenvolvimento do estágio. 
Entretanto, o que é objeto de reflexão neste ensaio é a possibilidade do estágio supervisionado favorecer o potencial que a atividade extensionista tem como uma metodologia no processo de aprendizagem, estabelecendo recursos mais duradouros e sistemáticos para o exercício da formação profissional com base na relação inseparável da teoria e da prática. Estas ações implicam em um aprofundamento do debate sobre a aplicabilidade do conhecimento no mundo contemporâneo e os seus fins. Este processo será marcado por disputas de áreas de conhecimento nas quais operam hierarquias de saber que vêm se consolidando ao longo da história da formação dos grupos profissionais. Avançar nesta direção será sempre uma vantagem, tendo em vista que pode favorecer o diálogo entre grupos diferenciados, a depender da forma como será conduzido o processo e do preparo de seus coordenadores. A maior expectativa existente nesta proposta é superar um processo de banalização da dimensão prática do conhecimento como se as avaliações sobre a aplicabilidade de determinados pressupostos ou hipóteses, a priori, apresentadas como científicas, não tivesse nenhuma relevância.

\section{Referências}

1. SILVA, Dayse de Paula Marques. Novas hierarquias profissionais: conhecimento, gênero e etnia e impacto sobre carreiras. Projeto de Pesquisa aprovado pelo PROCIÊNCIA/UERJ, 2009, com apoio da FAPERJ. Rio de Janeiro, 2009. 35 p.; Relações de gênero no campo profissional da Medicina. Tese de Doutorado - Programa de Pós-graduação em Sociologia IFCS/ Universidade Federal do Rio de Janeiro. Rio de Janeiro, 1998. 223 p.; Núcleo Estudos de Gênero, Geração e Etnia: demandas sociais e políticas públicas. Projeto aprovado no PROCIÊNCIA/UERJ, 1997, posteriormente implantado como Programa de Estudos e registrado como Programa de Extensão, reconhecido por ato executivo da reitoria em 2002; Carreira profissional e conciliação das tarefas domésticas em mulheres universitárias. Dissertação de mestrado - Programa de Posgraduação em Ciências Sociais no IFCS/Universidade Federal do Rio de Janeiro, 1989. 100 p.

2. BOTELHO, Maria das Graças. Os rumos da educação superior no Brasil e o ensino de graduação na Universidade do Estado do Rio de Janeiro: que universidade é possível? Dissertação (Mestrado) - Programa de Pós-graduação em Serviço Social da Universidade do Estado do Rio de Janeiro, Rio de Janeiro, 2004. 120 p.

3. ARRUDA, José Ricardo Campelo. Sistema UERJ de ensino, pesquisa, extensão e empregabilidade. Disponível em: http://www.sr1.uerj.br/cetreina/con- teudo.php?login $=\&$ sessionid $=\&$ referencia $=$ cetreina $\&$ codificacao $=027: 010$. Acesso em: jun. 2010 .

\section{Bibliografia}

BOURDIEU, Pierre. Oficio de Sociólogo. Petropolis: Vozes, 2004. $328 \mathrm{p}$.

Os usos sociais da ciência: por uma sociologia clínica do campo científico. São Paulo: Editora UNESP, 2004. 86 p.

. A economia das trocas simbólicas. São Paulo: Perspectiva, $1987.361 \mathrm{p}$.

BOURDIEU, Pierre; PASSERON, Jean Claude. A reprodução: elementos para uma teoria do sistema de ensino. Petrópolis: Vozes, 2008. 275 p.

COELHO, E. C. As profissões imperiais: medicina, engenharia e advocacia no Rio de Janeiro, 1822-1930. Rio de Janeiro: Record, 1999. 303 p.

CRUZ, Carla; RIBEIRO, Uirá. Metodologia cientifica: teoria e prática. 2 ed. Rio de Janeiro: Axcel Books do Brasil, $2004.340 \mathrm{p}$.

FICHTE, Johann Gottlieb. Por uma universidade orgânica. Coleção Universidade. Rio de Janeiro: Eduerj, 1999. $189 \mathrm{p}$.

FREIRE, Paulo. Pedagogia da autonomia. 36. ed. São Paulo: Paz e Terra, 2007. 92 p.

NOGUEIRA, Maria das Dores Pimentel (org). Extensão Universitária: diretrizes conceituais e políticas - Documentos básicos do Fórum Nacional de Pró-Reitores de Extensão das Universidades Públicas Brasileiras 1987 2000. Belo Horizonte: PROEX/UFMG; o Fórum, 2000.

ORTEGA y GASSET, José. Missão da Universidade. Rio de Janeiro: EDUERJ, 1999. $121 \mathrm{p}$.

PEREIRA, Antonio Celso et alli. Visão e Ação: a universidade no século XXI. Organização André Lázaro. Rio de Janeiro: $1999.118 \mathrm{p}$.

SILVA, D. P. M. Identidades no espaço universitário: gênero e etnia. Interseções. Revista de Estudos Interdisciplinares, Rio de Janeiro, Ano 9, n.2, p. 397- 409. 2007.

TEIXEIRA, Anísio. A universidade de ontem e de hoje. Rio de Janeiro: EDUERJ, 1998. 102 p.
Abstract
This article has as purpose offering some opin- ion about the knowledge applicability in the contemporary society and the potential that a practical formation has to support the advance in this debate. From the comparison between the extension action and the supervised intern- ship experiences, the different alternatives for consolidating the extension are explored as an important way of methodological consolidation for teaching experiences.
Keywords: Extension; Supervised internship; Education 